\title{
Physiological response to postural change during mild hypoglycaemia in patients with IDDM
}

\author{
A.M. Robinson ${ }^{1}$, H.M. Parkin ${ }^{2}$, 1. A. Macdonald ${ }^{2}$, R. B. TattersalI ${ }^{1}$ \\ 'Diabetes Unit, University Hospital, Queen's Medical Centre, Nottingham, UK \\ ${ }^{2}$ Department of Physiology and Pharmacology, University Hospital, Queen's Medical Centre, Nottingham, UK
}

\begin{abstract}
Summary It has been suggested that patients with insulin-dependent diabetes mellitus may be less aware of impending hypoglycaemia when lying than standing. We have studied the effect of posture and duration of hypoglycaemia on symptoms and physiological responses in 10 men with insulin-dependent diabetes. A standard tilting protocol was used (supine, $50^{\circ}, 90^{\circ}$ headup, and return to supine, $5 \mathrm{~min}$ at each position). At one visit patients were tilted before, $10 \mathrm{~min}$ after and $40 \mathrm{~min}$ after achieving hypoglycaemia (blood glucose $2.5 \mathrm{mmol} / \mathrm{l}$ ), and at another visit were tilted after euglycaemia $(5.0 \mathrm{mmol} / \mathrm{l})$ using a hyperinsulinaemic clamp. At each position, hormonal and physiological responses and symptoms (using visual analogue scales) were recorded. After $10 \mathrm{~min}$ of hypoglycaemia, adrenaline was significantly higher when $90^{\circ}$ headup compared with supine (mean $[ \pm \mathrm{SEM}] \quad 6.26[ \pm 1.88]$ vs $1.68[ \pm 0.4] \mathrm{nmol} / \mathrm{l}$; $p<0.05$ ), and fell significantly (to $2.46[ \pm 0.65]$
\end{abstract}

nmol/l; $p<0.05$ ) when returned to supine; sweating, symptom score and blood pressure followed a similar pattern. After 40 min of hypoglycaemia a similar effect of standing was seen on sweating, adrenaline and blood pressure but symptoms did not increase. Five patients underwent two further periods of hypoglycaemia, remaining supine or standing throughout. Face skin blood flow $(p<0.05)$ and temperature $(p=0.05)$ decreased when standing was maintained compared with lying. In conclusion, standing increases awareness of early hypoglycaemia and modifies many of the physiological changes. This increase in awareness is lost if hypoglycaemia is prolonged. [Diabetologia (1994) 37: 1241-1250]

Key words Posture, insulin-dependent diabetes mellitus, hypoglycaemia, adrenaline, adaptation to hypoglycaemia.
It has been suggested that sudden death in the night of patients with insulin-dependent diabetes mellitus (IDDM) may be connected with unawareness of hypoglycaemia [1]. A possible explanation is that, in patients who are asleep and often alone, impending hypoglycaemia may go unnoticed. However, a further contributory factor may be posture itself; lying down may reduce the physiological response to and aware-

Received: 17 March 1994

and in revised form: 16 June 1994

Corresponding author: Dr. A. M.Robinson, Diabetes Centre, Northern General Hospital, Sheffield S5 7AU, UK

Abbreviations: IDDM, Insulin-dependent diabetes mellitus; ANOVA, analysis of variance; bpm, beats per min. ness of hypoglycaemia. Hirsch et al. [2] showed increased patient hypoglycaemic awareness when standing but their study did not take into account the evolution of the physiological response, so leaving it unsure whether time or standing was responsible for the increase of hypoglycaemic awareness. The present study has been designed to clarify this by returning patients to the supine position after measurements in the standing position. If standing increases hypoglycaemic awareness there should be a reduction in the measured response when patients are moved back to the supine position despite a continuing evolution of symptoms. Furthermore, since Kerr et al. [3] demonstrated that patients with IDDM adapt to prolonged hypoglycaemia with a reduced symptomatic response and less cognitive dys- 
function, the protocol was extended to determine whether a similar adaptation to any effect of posture existed. Finally, to exclude the possible confounding effects of arousal or anxiety when frequent changes in posture occurred during the studies, half the patients returned for two further visits during which they remained lying or standing throughout while undergoing the hypoglycaemic part of the study.

\section{Subjects and methods}

Patients. Ten men with IDDM aged 20-35 years (mean 24.1), duration of diabetes 5-15 years (mean 9.2), $\mathrm{HbA}_{1} 6.4-9.5 \%$ (mean 8.5) (normal range 4-7.5\%), body mass index 20.7$25.1 \mathrm{~kg} / \mathrm{m}^{2}$ (mean 23.6) were recruited. None had diabetic complications apart from background retinopathy, and autonomic neuropathy was excluded by cardiovascular testing [4] and a normal acetylcholine sweatspot test [5]. All said that they were aware of when they were hypoglycaemic and none had a history of severe hypoglycaemia.

All patients gave written consent, and the study was approved by the University Hospital Ethical Committee.

\section{Protocol A: tilting in euglycaemic and hypoglycaemic states}

Experiments were performed on two occasions at least 2 weeks apart. At each visit patients were asked to inject their last dose of short- and medium-acting insulin at 18.00 hours the night before. They then fasted from midnight onward and attended the Diabetes Unit at 08.00 hours. A cannula was placed in an antecubital vein using local anaesthetic. Insulin (human Actrapid; Novo Nordisk Pharmaceuticals Ltd, Crawley, Sussex, UK) was infused continuously at variable rates to reduce blood glucose to $4-6 \mathrm{mmol} / \mathrm{l}$ and maintain it at this level for a minimum of $2 \mathrm{~h}$ before the study. The period of adjustment was standardised for each patient; therefore, each study took place at a similar time for that patient. The start varied between 11.00 and 12.30 hours and the experiment was cancelled if venous glucose level fell below $3.5 \mathrm{mmol} / \mathrm{l}$. All studies were performed at $25^{\circ} \mathrm{C}$ in a temperature-controlled environment.

After the stabilisation period patients were asked to lie on a horizontal tilt table (centrally pivoted) and, under local anaesthetic, a cannula was placed in a dorsal hand vein. The hand was then placed in a heated box $\left(55-60^{\circ} \mathrm{C}\right)$ in order to arterialise the venous samples and the cannula was kept patent with $150 \mathrm{mmol} / 1 \mathrm{NaCl}$. ECG electrodes, blood pressure cuff for automated oscillometric measurement (Accutorr 1A monitor; Datascope, Paramus, N.J., USA) and temperature probes (one attached to the cheek, one to the forehead) were positioned. Once patients were settled, they were familiarised with the tilting protocol (see below). The definitive tilt was performed three times at each visit. The first (basal) tilt was before a hyperinsulinaemic glucose clamp, when blood glucose was maintained between $4-6 \mathrm{mmol} / 1$, using an insulin infusion rate of $0.5-2.0 \mathrm{IU} / \mathrm{h}$. The cannula in the antecubital fossa was used for infusion of insulin at a fixed rate of $60 \mathrm{mU} \cdot \mathrm{m}^{-2} \cdot \mathrm{min}^{-1}$ and a variable infusion of $200 \mathrm{~g} / \mathrm{l}$ glucose with a modified hyperinsulinaemic clamp [6] to maintain arterialised blood glucose at predetermined levels. Glucose was administered by an IVAC 560 pump (IVAC, San Diego,
Calif., USA) and adjusted according to the blood glucose measured at the bedside (Yellow Springs Instruments, Yellow Springs, Ohio, USA).

On one visit blood glucose was maintained at $5 \mathrm{mmol} / 1$ throughout (Control visit), while on the other, it was allowed to fall to $2.5 \mathrm{mmol} / \mathrm{l}$ and then held at this level (Hypoglycaemia visit). The visits were performed in random order. After the blood glucose level had been held for $10 \mathrm{~min}$ at $2.5 \mathrm{mmol} /$ 1 , or at an equivalent time for the control visit, a further tilt (tilt 1) was performed. The final tilt (tilt 2) was performed after $40 \mathrm{~min}$ of hypoglycaemia or the corresponding time for the control visit. After the second tilt the insulin infusion was stopped and glucose returned to the normal range.

Tilt protocol and physiological measurements. Each tilt involved $5 \mathrm{~min}$ lying, followed by $5 \mathrm{~min}$ at $50^{\circ}, 5 \mathrm{~min}$ standing $\left(90^{\circ}\right)$, and then returning to the lying position for $5 \mathrm{~min}$. After 30 seconds at each position, cheek and forehead skin temperature (Comark Electronics, Rustington, Sussex, UK) were measured. Next sweat evaporation rate (Servomed, Stockholm, Sweden) and skin blood flow (MBF2 laser doppler flow monitor; Moor Instruments, Axminster, Devon, UK) were measured from the forehead and cheek. Simultaneously, blood was taken for catecholamine, insulin and glucose levels. Finally, heart rate and blood pressure were recorded. Patients completed a symptom questionnaire when lying at the end of the basal tilt, and at the end of each stage of tilts 1 and 2 . The symptom questionnaire consisted of nine questions each with a $100-\mathrm{mm}$ visual analogue scale; the left margin for minimal and the right for maximal symptoms. The questions were: facial flushing, trembling, palpitations, sweating, hunger (all classified as neurogenic), tingling, blurred vision, sleepiness (all neuroglycopenic/neurological) [7] and, finally what they believed their blood glucose level to be (i. e. "not hypoglycaemic" to "severely hypoglycaemic"). In addition, all patients were asked whether or not they felt hypoglycaemic ("Yes" or "No").

\section{Protocol B: induction of hypoglycaemia when lying or standing (fixed posture)}

Five of the original ten patients returned for two more visits separated by a minimum of 2 weeks. Blood glucose was again stabilised for $2 \mathrm{~h}$, but once on the tilt table patients were randomised to lie or stand for the rest of the study. Basal measurements were taken as in protocol A, the hyperinsulinaemic glucose clamp was started, and blood glucose was allowed to fall to $2.5 \mathrm{mmol} / \mathrm{l}$ as before. The period of adjustment was the same as in the previous experiments. Patients were not aware before the study started whether they were to remain euglycaemic throughout or whether they would be made hypoglycaemic.

After 10 min of stable hypoglycaemia, blood samples and physiological measurements were taken, and symptom scores assessed. Further measurements for the standing study were performed after 20,40,50 min of hypoglycaemia and, for the supine study, after $25,40,55 \mathrm{~min}$. These timings corresponded to measurements made during hypoglycaemia in protocol A at the start of each tilt and when the patients were in the same position as in protocol A. Glucose was then returned to normal.

Analytical procedures. Blood for catecholamine analysis was immediately centrifuged at 3,000 rev/ $\mathrm{min}$ for $10 \mathrm{~min}$. The plasma was added to tubes containing $75 \mu \mathrm{l}$ of EGTA-glutathione and stored at $-80^{\circ} \mathrm{C}$. Adrenaline and noradrenaline were 


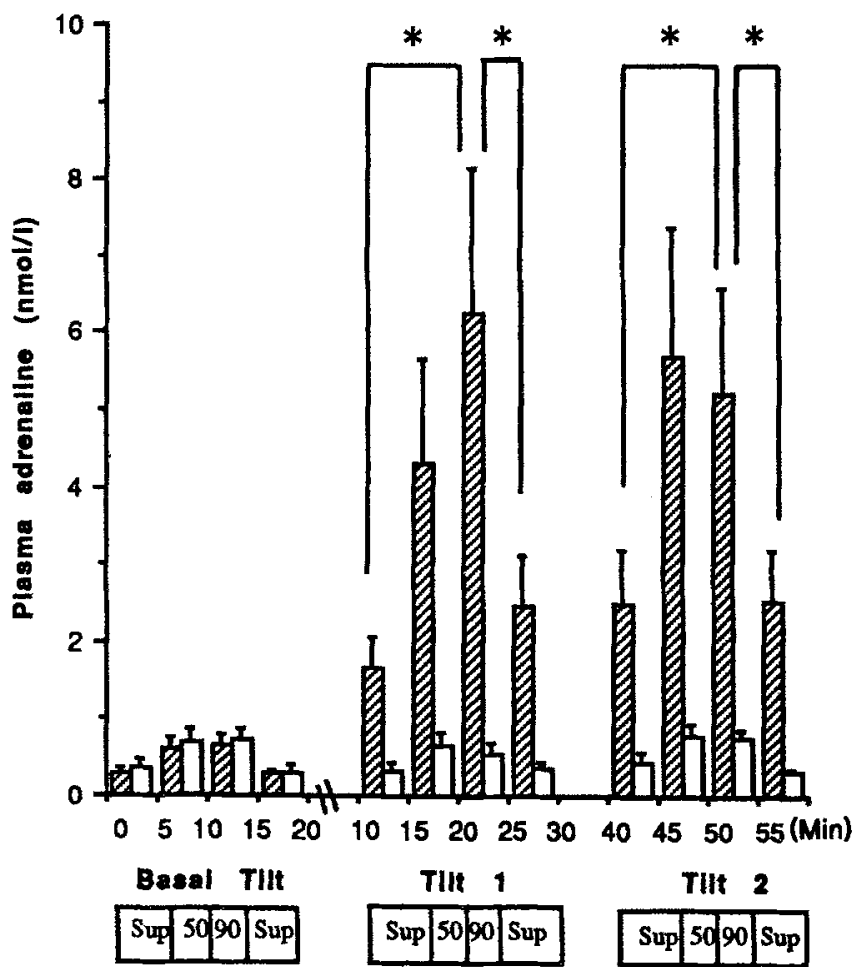

Fig. 1. Adrenaline levels: $\square$ hypoglycaemic visit, $\square$ euglycaemic visit * $p<0.05$

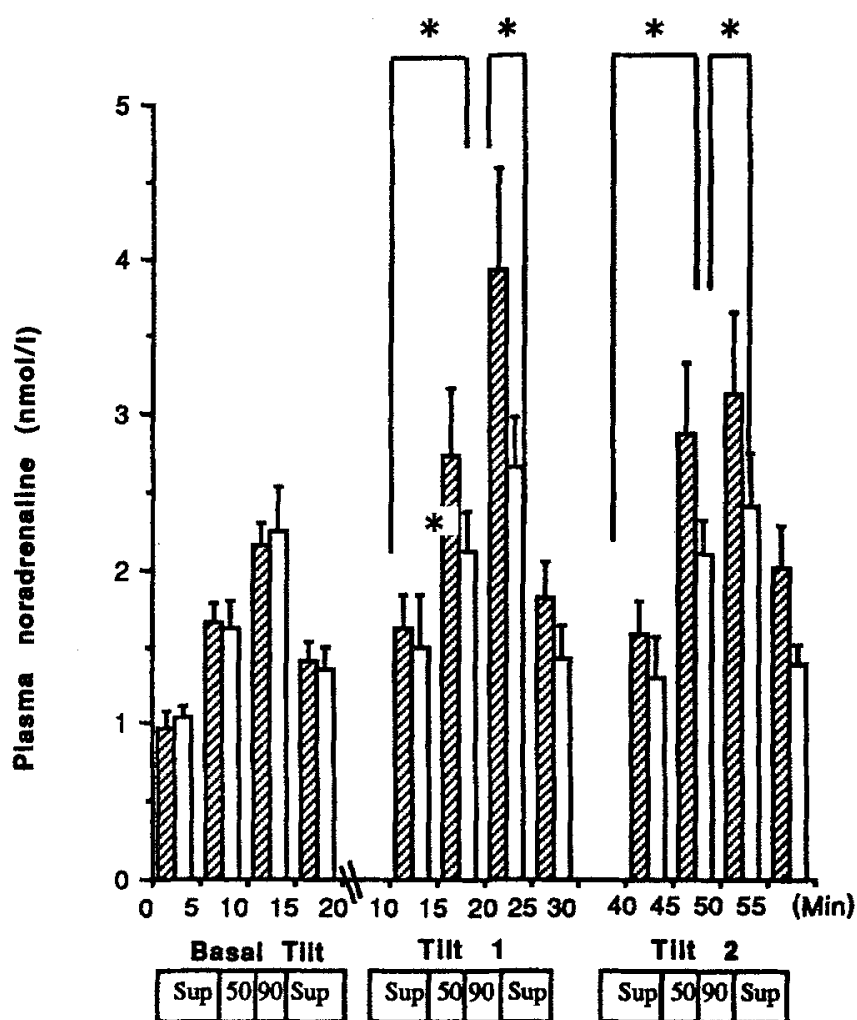

Fig. 2. Noradrenaline levels: $\square$ hypoglycaemic visit, $\square$ euglycaemic visit * $p<0.05$ measured in a batch by HPLC with electrochemical detection with intra-assay coefficients of variation of $8 \%$ and $6 \%$, respectively [8]. One subject's plasma contained an unidentified contaminant that made analysis impossible. Blood for insulin assay was similarly centrifuged and the plasma frozen. Total plasma insulin was measured by a standard radioimmunoassay.

Haemoglobin $\mathrm{A}_{1}$ was measured by mobile affinity electrophoresis on cellulose acetate membranes [9].

\section{Statistical analysis}

Statistical analysis was performed by analysis of variance (ANOVA) with paired $t$-tests if a significant visit effect was found $(p<0.05)$. Results are expressed as mean \pm SEM.

\section{Results}

\section{Protocol A: tilting}

In the quest for clarity, results with patients at $50^{\circ}$ are represented on all graphs and were used in the ANOVA analysis, but are not the subject of further statistical analysis. Suffice it to say that they represent a middle ground between the supine and standing positions.

\section{Baseline}

The expected physiological responses to tilting were observed (eg. an increase in plasma catecholamines (Figs. 1,2), but there were no significant differences between the values recorded on the two occasions. Baseline blood glucose values during the euglycaemic visit were $4.89 \pm 0.24$ when lying, $4.94 \pm 0.25$ at $50^{\circ}, \quad 5.06 \pm 0.28$ when standing, and $5.06 \pm 0.29$ $\mathrm{mmol} / \mathrm{l}$ when the patient was returned to the lying position. The corresponding values during the hypoglycaemic visit were $4.9 \pm 0.24,4.96 \pm 0.25,5.11 \pm 0.25$, $5.15 \pm 0.23 \mathrm{mmol} / 1$. Plasma insulin levels were similar during both baseline periods $18.2 \pm 3.2$ for the euglycaemic day, and $19.4 \pm 3.4 \mathrm{mU} / 1$ for the hypoglycaemic day. These levels are consistent with post-prandial insulin values and therefore unlikely to enhance the sympathetic response to forthcoming experiments.

\section{Tilts 1 and 2}

\section{Euglycaemic vs hypoglycaemic visit}

Blood glucose and insulin: Target blood glucose levels during the two tilt sequences were achieved (Fig.3). Plasma insulin levels were not significantly different during or between study days, but were obviously well above those values seen in the clinical situation $(122 \pm 6.5$ at $10 \mathrm{~min}$ and $129 \pm 7.1 \mathrm{mU} / \mathrm{l}$ at $40 \mathrm{~min}$ for 


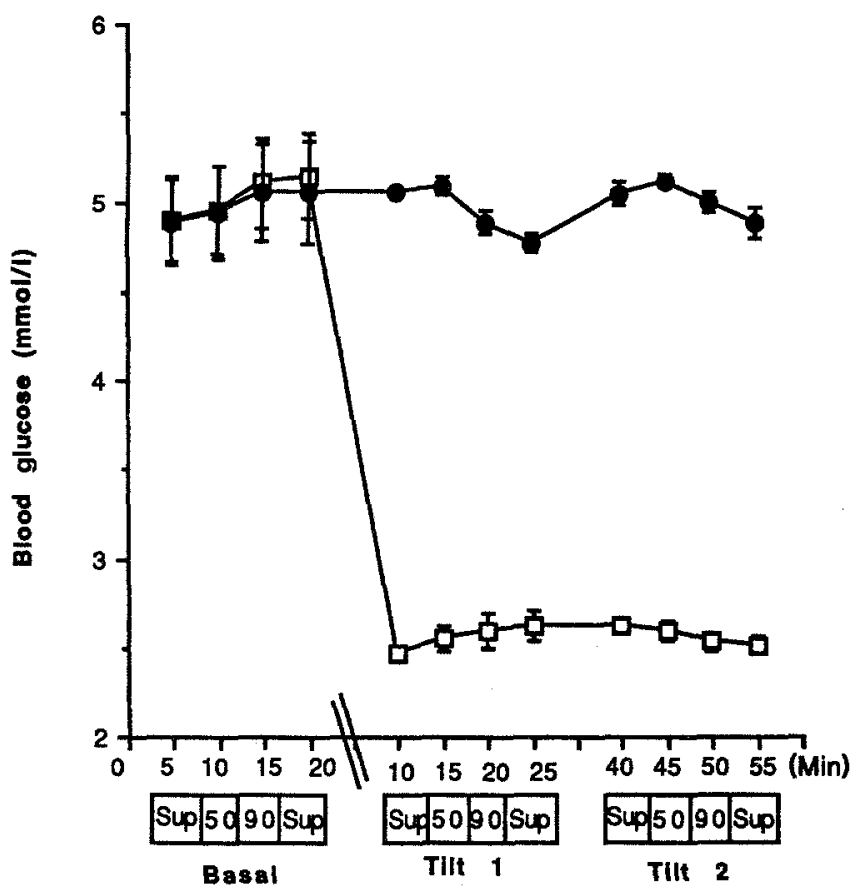

Fig. 3. Blood glucose levels: $\square$ hypoglycaemic visit, - euglycaemic visit

the euglycaemic visit and $125.6 \pm 11.2$ and $120.4 \pm 12.3 \mathrm{mU} / \mathrm{l}$ for the hypoglycaemic visit).

Plasma adrenaline and noradrenaline. Mean basal plasma adrenaline levels during the euglycaemic visit were similar to baseline values. All levels rose as patients became more upright. The values for the tilt sequences during the euglycaemic clamp were $0.32 \pm 0.12 \mathrm{nmol} / 1$ when lying at $10 \mathrm{~min}$ (tilt 1 ), $0.66 \pm$ 0.16 at $50^{\circ}, 0.56 \pm 0.11$ at $90^{\circ}$, and $0.35 \pm 0.09 \mathrm{nmol} / 1$ when returned to the supine; for tilt 2 , the values were $0.44 \pm 0.13,0.79 \pm 0.14,0.75 \pm 0.13$ and $0.32 \pm$ 0.04 , respectively. Levels during the hypoglycaemic clamp rose significantly $(p<0.001)$ when compared to the euglycaemic visit to $1.68 \pm 0.4,4.31 \pm 1.35$, $6.25 \pm 1.88,2.46 \pm 0.7 \mathrm{nmol} / 1$ for the corresponding positions in tilt 1 , and $2.51 \pm 0.69,5.68 \pm 1.72,5.2 \pm$ $1.41,2.55 \pm 0.64$ for tilt 2 (Fig. 1 ). As expected plasma noradrenaline rose significantly $(p<0.005)$ on all visits when patients were moved from lying to standing, and fell significantly $(p<0.005)$ when patients were returned to the supine position (Fig. 2). There was a small increase in noradrenaline during the euglycaemic clamp compared with the baseline values, but this was not significant. There was, however, a significant rise in noradrenaline values during the hypoglycaemic compared with the euglycaemic clamp $(p<0.05)$.

Physiological measurements. Moving patients from supine to $50^{\circ}$ and then to $90^{\circ}$ resulted in an increase in heart rate that was similar for both visits and both tilts, e.g. euglycaemic visit during tilt 1: supine $68.6 \pm 4.1,83.8 \pm 5.3$ at $50^{\circ}, 91.6 \pm 7.7$ beats per min (bpm) upright, the equivalent values for the hypoglycaemic visit were $69.3 \pm 4.7,85.8 \pm 5.4,96.6 \pm$ $5.2 \mathrm{bpm}$. These values were slightly but not significantly higher than during the baseline tilt.

Systolic blood pressure followed a similar pattern but was significantly higher during the hypoglycaemic than the euglycaemic visit $(p<0.05)$ i.e. for tilt 1 during the euglycaemic visit supine systolic pressure was $124 \pm 4 \mathrm{~mm} \mathrm{Hg}$, at $50^{\circ} 131 \pm 4 \mathrm{~mm} \mathrm{Hg}$ and when standing $130 \pm 3 \mathrm{~mm} \mathrm{Hg}$, the equivalent values during the hypoglycaemic visit were $136 \pm 4,143 \pm 3$ and $145 \pm 4 \mathrm{~mm} \mathrm{Hg}$.

Diastolic pressure also rose with more upright posture and increased significantly $(p<0.05)$ during hypoglycaemia. This was most noticeable at $90^{\circ}(78 \pm 3$ vs $71 \pm 2 \mathrm{mmHg} p<0.01$ during tilt 1 , and $79 \pm 4$ vs $70 \pm 2 \mathrm{~mm} \mathrm{Hg} p<0.05$ during tilt 2). This resulted in pulse pressures for tilt 1 during the euglycaemic visit when supine of $58 \pm 3 \mathrm{~mm} \mathrm{Hg}$, at $50^{\circ} 61 \pm 2$, and $59 \pm 2 \mathrm{~mm} \mathrm{Hg}$ when standing, which were significantly lower $(p<0.05)$ than those seen during hypoglycaemia, when supine $67 \pm 4$, at $50^{\circ} 66 \pm 3$ and when standing $67 \pm 3 \mathrm{~mm} \mathrm{Hg}$.

Sweating rates increased when the patient was made more upright on all occasions, but there was no difference between the euglycaemic and baseline phases. However, sweating during the hypoglycaemic clamp was significantly greater when compared with the euglycaemic clamp if measured on the forehead $(p<0.001)$ (Fig. 4$)$ and cheek $(p<0.05)$. Forehead sweating differences $(p<0.05)$ became apparent after $20 \mathrm{~min}$ of hypoglycaemia, i.e. at $90^{\circ}$ during tilt 1 and were maintained for the rest of the study. Individual cheek sweating rates only became significantly different at the final reading of the second tilt. Skin temperature was generally lower during the hypoglycaemic clamp (on the forehead $34.6 \pm 0.3^{\circ} \mathrm{C}$ after $10 \mathrm{~min}$ to $33.9 \pm 0.4^{\circ} \mathrm{C}$ at the end of tilt 2 , and on the cheek $34.4 \pm 0.4$ to $33.6 \pm 0.5^{\circ} \mathrm{C}$ ) compared with the euglycaemic clamp $\left(34.6 \pm 0.2^{\circ} \mathrm{C}\right.$ after $10 \mathrm{~min}$ to $34.7 \pm 0.3$ on the forehead, and $34.3 \pm 0.4$ to $34.2 \pm 0.5^{\circ} \mathrm{C}$ on the cheek) but these results are not statistically different.

Blood flow at each site was reduced during the hypoglycaemic clamp when patients were moved to the standing position (on the forehead $0.52 \pm 0.08$ vs $0.57 \pm 0.07^{\circ} \mathrm{C}$ vs during tilt 1 , and $0.49 \pm 0.08$ vs $0.6 \pm 0.07^{\circ} \mathrm{C}$ during tilt 2 : on the cheek $0.74 \pm 0.11$ vs $0.9 \pm 0.15^{\circ} \mathrm{C}$ and $0.92 \pm 0.15$ vs $0.96 \pm 0.17^{\circ} \mathrm{C}$ ).

Symptoms. These data are presented as the change from baseline for each clamp. As individual components or when amalgamated, there were no significant changes from the baseline during the euglycaemic phase. The combined sum of symptoms during the hypoglycaemic clamp increased significantly $(p<0.005)$, as expected. This difference was present throughout the study period (Fig. 5). 


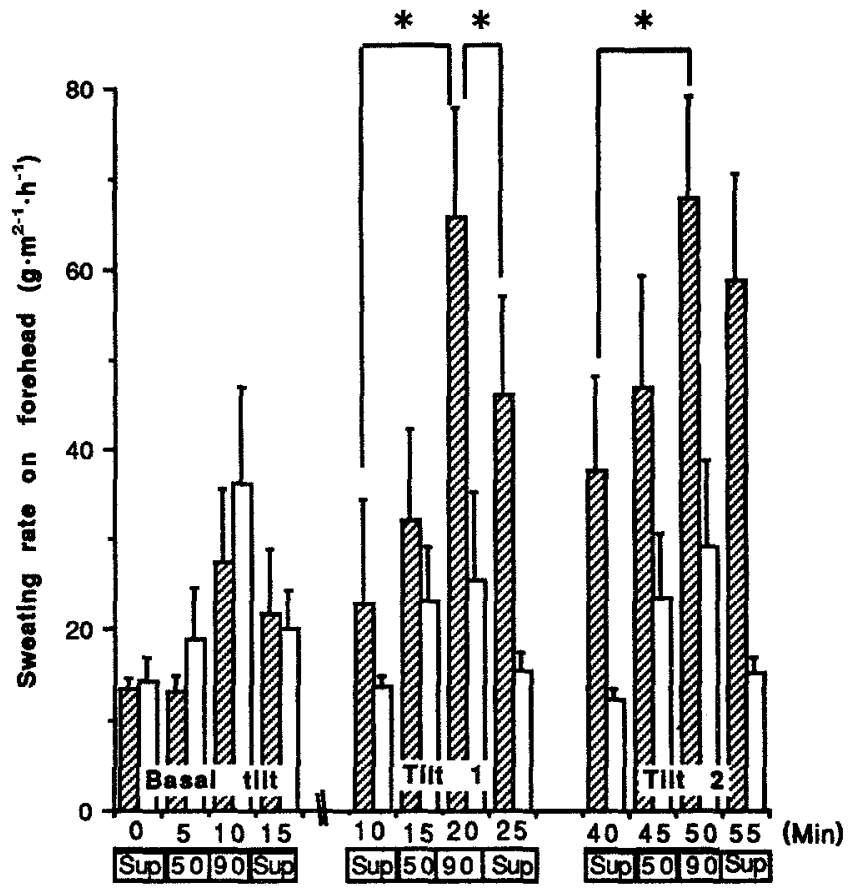

Fig.4. Sweating response: $\square$ hypoglycaemic visit, $\square$ euglycaemic visit $* p<0.05$

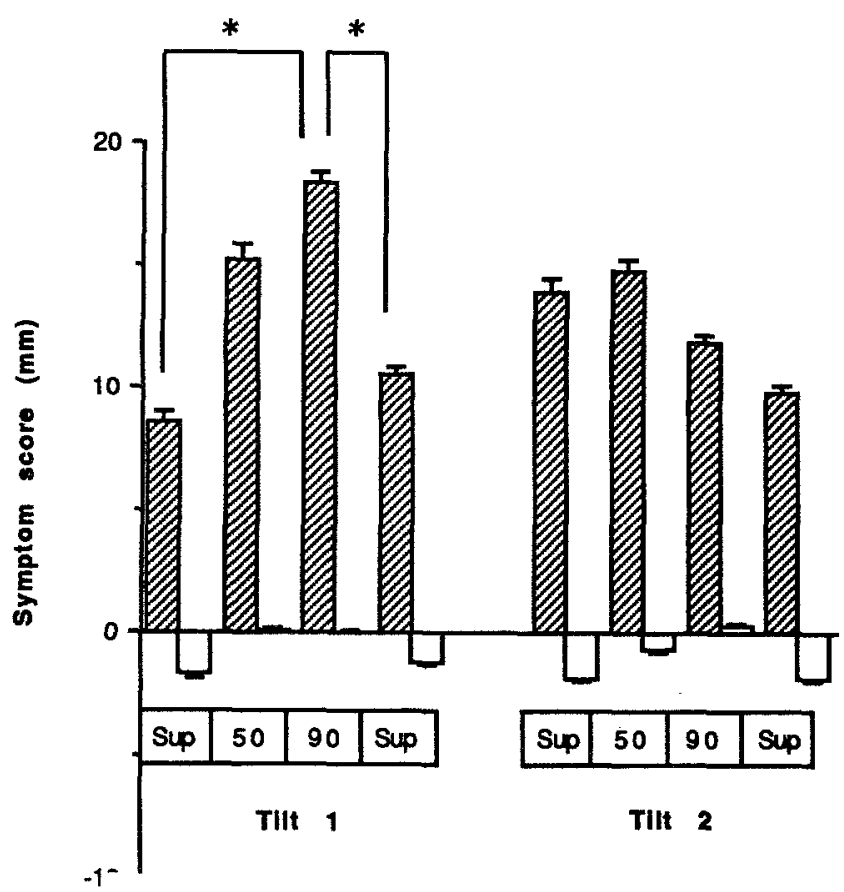

Fig.5. Symptom score: $\square$ hypoglycaemic visit, $\square$ euglycaemic visit $* p<0.05$

Effects of postural change during the hypoglycaemic visit: This refers to the results obtained during the hypoglycaemic visit, and provides the information to assess what effect the position of the patients had on their physiological and symptomatic response to hypoglycaemia. Diastolic blood pressure, adrenaline and noradrenaline levels and sweating rates (on the forehead) all rose significantly $(p<0.05)$ when patients were moved to $90^{\circ}$ during tilt 1 (Table 1 ), and fell significantly $(p<0.05)$ when they were returned to lying. The same physiological changes were seen during tilt 2 , except that sweating continued at a similar rate when patients were returned to the lying position.

Patients became significantly $(p<0.005)$ more symptomatic when moved from lying to $90^{\circ}$ in tilt 1 , and this was followed by a significant $(p<0.05)$ reduction in symptoms when they lay down again. Furthermore, if the symptoms are divided into neurogenic or neuroglycopenic/neurological, neurogenic symptoms (sweating, flushing, trembling, palpitations and hunger) increased significantly $(8.04 \mathrm{~mm}$ vs $22.6 \mathrm{~mm}$ $p<0.01$ ) from lying to standing, followed by a significant reduction when returned to lying (12.08, $p<0.05$ ). Sweating, flushing and trembling showed the most change with posture change. Neuroglycopenic symptoms (sleepiness, blurred vision and tingling) were unaffected by position. In response to the question about how hypoglycaemic they felt patients reported an increase $(25.9 \pm 8.2 \mathrm{~mm}$ vs $37.2 \pm 10.5 \mathrm{~mm}$, $p<0.05)$ when moved from lying to standing and a significant fall (to $26.3 \pm 8.9, p<0.05$ ) when returned to lying. The most positive responses ( 6 of 10 ) to the direct question: "Are you hypoglycaemic? Yes or No" were received during tilt 1 at $90^{\circ}$. In tilt 2 however, symptoms were unaffected by posture (Fig.5).

\section{Protocol B: fixed posture}

Results were compared with only the five patients in protocol A. Glucose and insulin levels were the same as in protocol A. The results have been compared with those obtained during the tilting protocol to determine whether tilting the patients affected the responses observed (i). Further assessment compares the results obtained in the two visits of the protocol (ii).

i) Comparison of results with Protocol A: tilting. There were no differences between the catecholamine response during the lying or standing visits when compared with the equivalent timings during the hypoglycaemic tilt visit (Tables 2,3).

Physiological measurements were consistent with those during the first protocol although there was a marked reduction in skin temperature, especially on the forehead, after $50 \mathrm{~min}$ of hypoglycaemia ( $34.9 \pm 0.1$ vs $32.5 \pm 0.8^{\circ} \mathrm{C}, p=0.056$ ), when patients stood throughout. There was also a reduction in blood flow on the forehead and cheek during both visits. However, the baseline measurements were not consistent with those of the tilting protocol A, and therefore no direct comparison could be made.

ii) Comparison of lying vs standing results from Protocol B: fixed posture. When at $90^{\circ}$, heart rate was 
Table 1. Effect of posture on physiological responses to hypoglycaemia

\begin{tabular}{|c|c|c|c|c|c|c|}
\hline & \multicolumn{3}{|l|}{ Tilt 1} & \multicolumn{3}{|l|}{ Tilt 2} \\
\hline & $\begin{array}{l}10 \mathrm{~min} \\
\text { Supine }\end{array}$ & $\begin{array}{l}20 \text { min } \\
\text { Standing }\end{array}$ & $\begin{array}{l}25 \text { min } \\
\text { Supine }\end{array}$ & $\begin{array}{l}40 \text { min } \\
\text { Supine }\end{array}$ & $\begin{array}{l}50 \text { min } \\
\text { Standing }\end{array}$ & $\begin{array}{l}55 \text { min } \\
\text { Supine }\end{array}$ \\
\hline $\begin{array}{l}\text { Adrenaline } \\
(\mathrm{nmol} / 1)\end{array}$ & $1.68^{\mathrm{a}} \pm 0.40$ & $6.25 \pm 1.88$ & $2.46^{a} \pm 0.65$ & $2.51^{\mathrm{a}} \pm 0.69$ & $5.20 \pm 1.41$ & $2.55^{\mathrm{a}} \pm 0.64$ \\
\hline $\begin{array}{l}\text { Noradrenaline } \\
(\mathrm{nmol} / 1)\end{array}$ & $1.61^{\mathrm{a}} \pm 0.22$ & $3.90 \pm 0.07$ & $1.81^{a} \pm 0.23$ & $1.59^{\mathrm{a}} \pm 0.21$ & $3.14 \pm 0.52$ & $2.02^{a} \pm 0.26$ \\
\hline $\begin{array}{l}\text { Sweating (forehead) } \\
\left(\mathrm{g} \cdot \mathrm{m}^{2} \cdot \mathrm{h}^{-1}\right)\end{array}$ & $23.0^{\mathrm{a}} \pm 11.4$ & $66.2 \pm 11.8$ & $46.0^{\mathrm{a}} \pm 11.2$ & $37.6^{a} \pm 10.6$ & $68.2 \pm 10.8$ & $58.9 \pm 11.9$ \\
\hline $\begin{array}{l}\text { Systolic BP } \\
(\mathrm{mm} \mathrm{Hg})\end{array}$ & $135.7 \pm 4.1$ & $144.7 \pm 3.9$ & $138.5 \pm 4.6$ & $136.2 \pm 5.1$ & $141.8 \pm 6.5$ & $138.7 \pm 4.6$ \\
\hline $\begin{array}{l}\text { Diastolic BP } \\
(\mathrm{mm} \mathrm{Hg})\end{array}$ & $67.9^{a} \pm 3.7$ & $77.6 \pm 2.9$ & $69.3^{a} \pm 3.5$ & $68.2^{\mathrm{a}} \pm 3.5$ & $79.1 \pm 3.7$ & $68.6^{a} \pm 3.5$ \\
\hline $\begin{array}{l}\text { Symptom score } \\
(\mathrm{mm})\end{array}$ & $8.60^{\mathrm{a}} \pm 0.38$ & $18.38 \pm 0.48$ & $10.54^{\mathrm{a}} \pm 0.34$ & $13.90 \pm 0.50$ & $11.8 \pm 0.35$ & $9.8 \pm 0.31$ \\
\hline
\end{tabular}

Data given as mean \pm SEM

a significant change from upright position $p<0.05$

Table 2. Comparison of supine values for protocol A (tilting) and B (fixed posture)

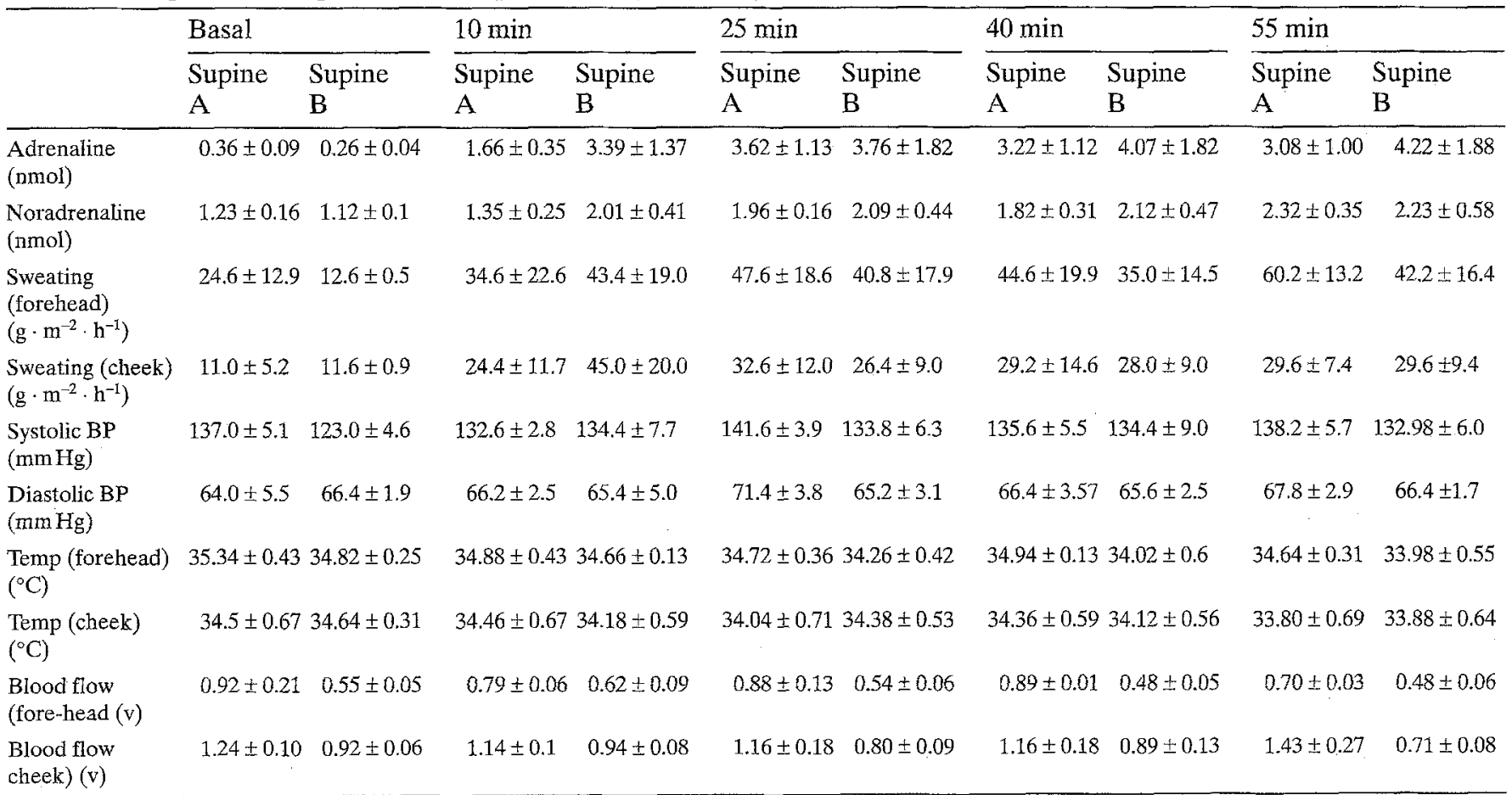

Data given as mean \pm SEM

significantly higher before and during the hypoglycaemic challenge $(p<0.05)$, (i.e. after $10 \mathrm{~min}$ of hypoglycaemia $104 \pm 11$ vs $79 \pm 8 \mathrm{bpm}$ when lying). This was seen during both hypoglycaemic and euglycaemic studies of the tilting protocol $A$, and is therefore related to position rather than hypoglycaemia.

When the patients were at $90^{\circ}$, measurements of diastolic blood pressure $(p<0.05)$ and sweating $(p<0.05)$ increased significantly over those when lying when patients were hypoglycaemic. There was also a rise in systolic pressure as in the hypoglycae- mic tilt of protocol A (tilting); this however failed to reach significance.

Adrenaline levels were consistently higher at $90^{\circ}$ throughout compared with lying (at $10 \mathrm{~min} 7.44$ vs 3.39 and at $40 \mathrm{~min} 7.49$ vs $4.07 \mathrm{nmol} / 1$ ). Similarly, noradrenaline levels were significantly higher when standing.

Cheek temperature remained significantly lower when standing before the hypoglycaemic challenge $\left(33.7 \pm 0.2\right.$ vs $34.6 \pm 0.3^{\circ} \mathrm{C}$ ) as well as during the procedure. On the other hand, forehead temperature was similar before the hypoglycaemic challenge 
Table 3. Comparison of standing values for Protocols A (tilting) and B (fixed posture)

\begin{tabular}{|c|c|c|c|c|c|c|}
\hline & \multicolumn{2}{|l|}{ Basal } & \multicolumn{2}{|l|}{$20 \mathrm{~min}$} & \multicolumn{2}{|l|}{$50 \mathrm{~min}$} \\
\hline & $\begin{array}{l}\text { Standing } \\
\text { A }\end{array}$ & B & $\begin{array}{l}\text { Standing } \\
\text { A }\end{array}$ & B & $\begin{array}{l}\text { Standing } \\
\text { A }\end{array}$ & $\mathrm{B}$ \\
\hline $\begin{array}{l}\text { Adrenaline } \\
(\mathrm{mmol} / \mathrm{l})\end{array}$ & $0.82 \pm 0.17$ & $0.43 \pm 0.12$ & $5.70 \pm 1.70$ & $7.49 \pm 2.90$ & $5.85 \pm 2.40$ & $8.0 \pm 2.53$ \\
\hline $\begin{array}{l}\text { Noradrenaline } \\
(\mathrm{nmol} / \mathrm{I})\end{array}$ & $2.04 \pm 0.19$ & $1.98 \pm 0.20$ & $3.58 \pm 0.45$ & $5.52 \pm 1.35$ & $3.68 \pm 0.86$ & $3.71 \pm 0.82$ \\
\hline $\begin{array}{l}\text { Sweating (forehead) } \\
\left(\mathrm{g} / \mathrm{m}^{2}\right)\end{array}$ & $32.2 \pm 15.1$ & $17.8 \pm 7.15$ & $56.0 \pm 18.9$ & $74.6 \pm 17.1$ & $54.8 \pm 16.5$ & $56.8 \pm 16.5$ \\
\hline $\begin{array}{l}\text { Sweating (cheek) } \\
\left(\mathrm{g} / \mathrm{m}^{2}\right)\end{array}$ & $21.8 \pm 9.7$ & $12.6 \pm 2.8$ & $35.8 \pm 11.5$ & $45.8 \pm 14.6$ & $34.6 \pm 10.2$ & $34.0 \pm 13.3$ \\
\hline $\begin{array}{l}\text { Systolic BP } \\
(\mathrm{mmHg})\end{array}$ & $130.8 \pm 4.0$ & $135.0 \pm 6.45$ & $145.8 \pm 6.0$ & $135.0 \pm 7.1$ & $135.2 \pm 9.4$ & $144.8 \pm 6.6$ \\
\hline $\begin{array}{l}\text { Diastolic BP } \\
(\mathrm{mmHg})\end{array}$ & $72.0 \pm 2.4$ & $73.0 \pm 4.75$ & $73.6 \pm 3.5$ & $78.2 \pm 3.6$ & $75.6 \pm 3.6$ & $75.8 \pm 2.8$ \\
\hline $\begin{array}{l}\text { Temp (forehead) } \\
\left({ }^{\circ} \mathrm{C}\right)\end{array}$ & $35.08 \pm 0.31$ & $34.80 \pm 0.18$ & $34.90 \pm 0.31$ & $32.38 \pm 0.76$ & $34.70 \pm 0.30$ & $32.52 \pm 0.78$ \\
\hline $\begin{array}{l}\text { Temp (cheek) } \\
\left({ }^{\circ} \mathrm{C}\right)\end{array}$ & $33.86 \pm 0.71$ & $33.66 \pm 0.19$ & $33.76 \pm 0.60$ & $32.72 \pm 0.91$ & $33.40 \pm 0.76$ & $32.04 \pm 1.15$ \\
\hline $\begin{array}{l}\text { Blood flow } \\
\text { (fore-head) (v) }\end{array}$ & $0.72 \pm 0.13$ & $0.524 \pm 0.043$ & $0.59 \pm 0.12$ & $0.528 \pm 0.035$ & $0.52 \pm 0.13$ & $0.548 \pm 0.045$ \\
\hline Blood flow (cheek)(v) & $1.21 \pm 0.13$ & $0.79 \pm 0.035$ & $0.93 \pm 0.17$ & $0.53 \pm 0.053$ & $1.19 \pm 0.26$ & $0.554 \pm 0.052$ \\
\hline
\end{tabular}

Data given as mean \pm SEM

( $34.8 \pm 0.2$ vs $34.8 \pm 0.3^{\circ} \mathrm{C}$ ) but upon standing, fell significantly during hypoglycaemia $(p<0.05$ : Fig. 6$)$. Cheek blood flow fell significantly during the hypoglycaemic challenge $(p<0.05)$ when patients were at $90^{\circ}$ (Fig. 7).

Symptom scores were consistent with the previous hypoglycaemic challenge in protocol $\mathrm{A}$, showing a similar increase at $90^{\circ}$ (at $10 \mathrm{~min}$ score $=32.1$ vs $20.3 \mathrm{~mm}$ : at $40 \mathrm{~min}$ score $=31.4$ vs $21 \mathrm{~mm}$ ). Hypoglycaemic symptoms showed the biggest difference after $10 \mathrm{~min}$ of hypoglycaemia $\left(36.8 \pm 16.9\right.$ at $90^{\circ}$ to $27.6 \pm 12.1 \mathrm{~mm}$ when lying) and, furthermore, in answer to the question "Do you feel hypoglycaemic?", three patients said "yes" when standing compared to two when lying at $10 \mathrm{~min}$. Again, standing had less effect on the overall symptom score as the hypoglycaemia was prolonged (score 28.6 at $50 \mathrm{~min}$ vs $31.4 \mathrm{~mm}$ after $40 \mathrm{~min}$ ), whilst the score when lying was maintained (22.2 $\mathrm{mm}$ at $55 \mathrm{~min}$ vs $21 \mathrm{~mm}$ after $40 \mathrm{~min}$ ).

\section{Discussion}

Our findings confirm that the symptoms of hypoglycaemia are more intense when patients are standing than when lying. The significant reduction of physiological signs and symptoms that occurs when returning the patients to the supine position excludes the possibility that these changes are related to the evolution of hypoglycaemic symptoms, and must therefore be a result of posture. Also, the continued physiologi- cal response to hypoglycaemia beyond $40 \mathrm{~min}$ excludes the possibility that changes in the first tilt are related to the hypoglycaemic response waning. Furthermore, increases in catecholamines, sweating and blood pressure when patients stood throughout confirm that the increases seen during tilting are real and are not a result of increased arousal or anxiety due to a change in position. Indeed, the only significant differences between the two protocols (i.e. the reductions in skin temperature and blood flow seen when patients stood throughout), should theoretically increase perception of hypoglycaemia. We think the reason that these physiological differences were not seen during the tilting protocol relates to the short time patients were maintained in one position, which would not allow these relatively slow physiological responses to reach equilibrium. In particular, temperature measurements were made after only $30 \mathrm{~s}$ in the new position and in retrospect this period was too short for the effect of position to influence the results.

Increased awareness of hypoglycaemia when standing probably results from the enhanced sweating and plasma adrenaline, especially as it was predominantly the neurogenic symptoms which were increased. Moving from lying to standing is accompanied by increased sympathetic nervous system activity (giving a rise in plasma noradrenaline) and to a lesser extent by increased adrenaline and possibly noradrenaline from the adrenal medulla [10], and the present study shows that this effect is magnified by hypoglycaemia. In fact the plasma adrenaline re- 


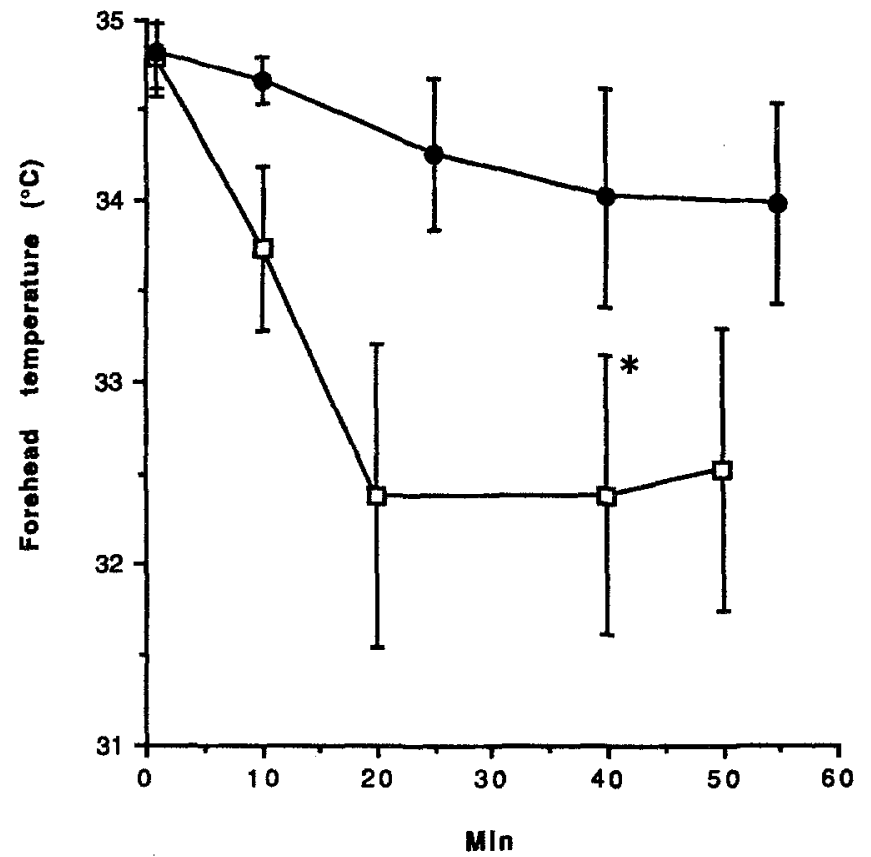

Fig. 6. (protocol B) Forehead temperature: $\square$ hypoglycaemic visit, euglycaemic visit $* p<0.05$

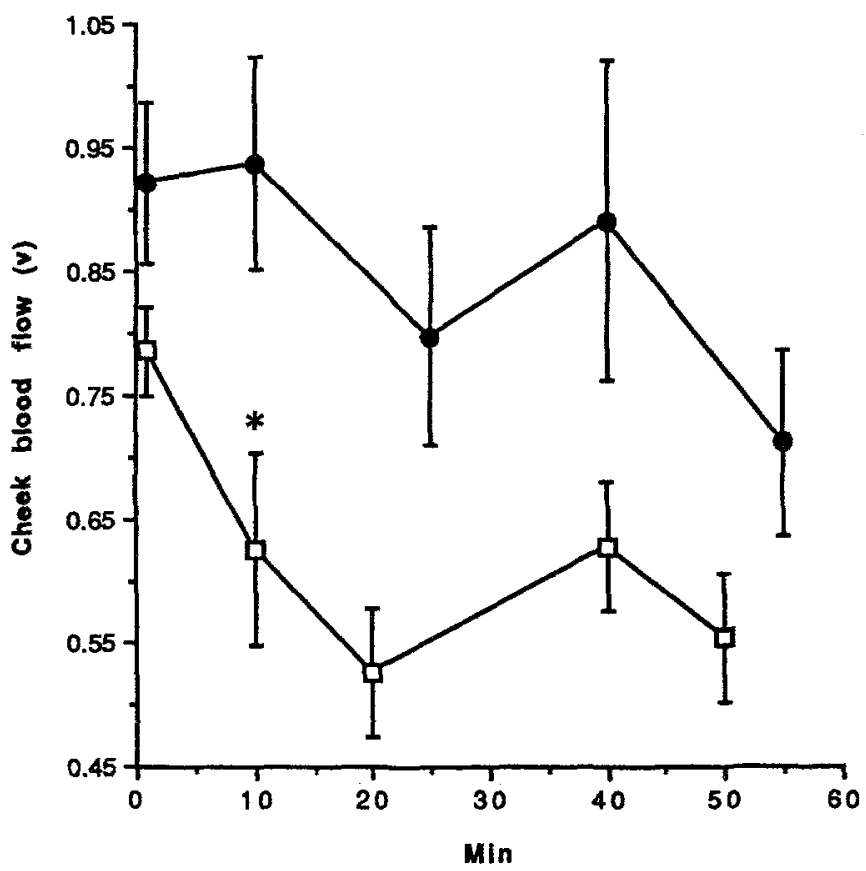

Fig. 7. (protocol B) Blood flow: $\square$ hypoglycaemic visit, - euglycaemic visit * $p<0.05$

sponse when standing and hypoglycaemic was even greater than would be expected if the two effects were simply additive, suggesting a multiplicative or synergistic effect. By contrast the noradrenaline response appears to be merely additive. We also confirm previous observations $[2,11]$ that the plasma noradrenaline response to standing is more marked than that to hypoglycaemia (which is not that much greater than the effect of insulin per se). The more marked synergism between standing and hypoglycaemia of the adrenaline rather than the noradrenaline response suggests a link with counterregulation, as adrenaline is the more important counterregulatory catecholamine. Furthermore, the sweating response was enhanced when standing, indicative of a more potent hypoglycaemic stimulus. It is possible that when standing and hypoglycaemic there is a reduction in cerebral blood flow which reduces cerebral glucose delivery and increases the hypoglycaemic stimulus. In the upright position a fall in cerebral blood flow would normally be expected because of a decrease in mean arterial blood pressure compared to the supine or euglycaemic states. However, when standing and hypoglycaemic, systolic blood pressure was similar to the euglycaemic values and diastolic blood pressure actually increased. Thus, if cerebral blood flow was reduced during hypoglycaemia whilst standing, it must have been due to cerebral vasoconstriction.

In normal individuals and in the early years of IDDM, hypoglycaemia is accompanied by an increase in systolic pressure with a reduction in the diastolic pressure, leading to a widening in pulse pressure which is perceived as palpitations. In this study there was the expected systolic increase which was enhanced with upright posture, but the diastolic blood pressure increased compared with the euglycaemic visit, an effect enhanced by standing. This was despite the adrenaline levels being well above the threshold to cause falls in diastolic pressure and an increase in heart rate [12]. Therefore, further contributory factors must be involved. Since these changes are regulated by both alpha- and beta-adrenoceptors, where alpha mediate vasoconstriction and beta vasodilatation, it is possible that alpha-receptors are dominant when standing. This would explain why there was no increase in heart rate during hypoglycaemia. There was an increase in heart rate on standing, but this was similar to the euglycaemic visit. This suggests that the response is related to the known changes associated with postural change rather than any direct effect of hypoglycaemia. A reduced heart rate response has been seen before in well-controlled diabetic patients with reduced adrenaline responses [13] and in patients with long duration of diabetes [14] and is a feature of beta-adrenergic blockade in normal subjects during hypoglycaemia. The patients in this study had medium to long duration of wellcontrolled diabetes, as well as reduced adrenaline responses compared with normal subjects. It is possible that reduced beta-adrenoceptor sensitivity also contributed to the responses seen.

Alpha-adrenoceptor stimulation may also have contributed to the changes in sweating rates. Sweating is usually mediated through sympathetic cholinergic stimulation, but there is a minor component due 
Table 3. Comparison of standing values for Protocols A (tilting) and B (fixed posture)

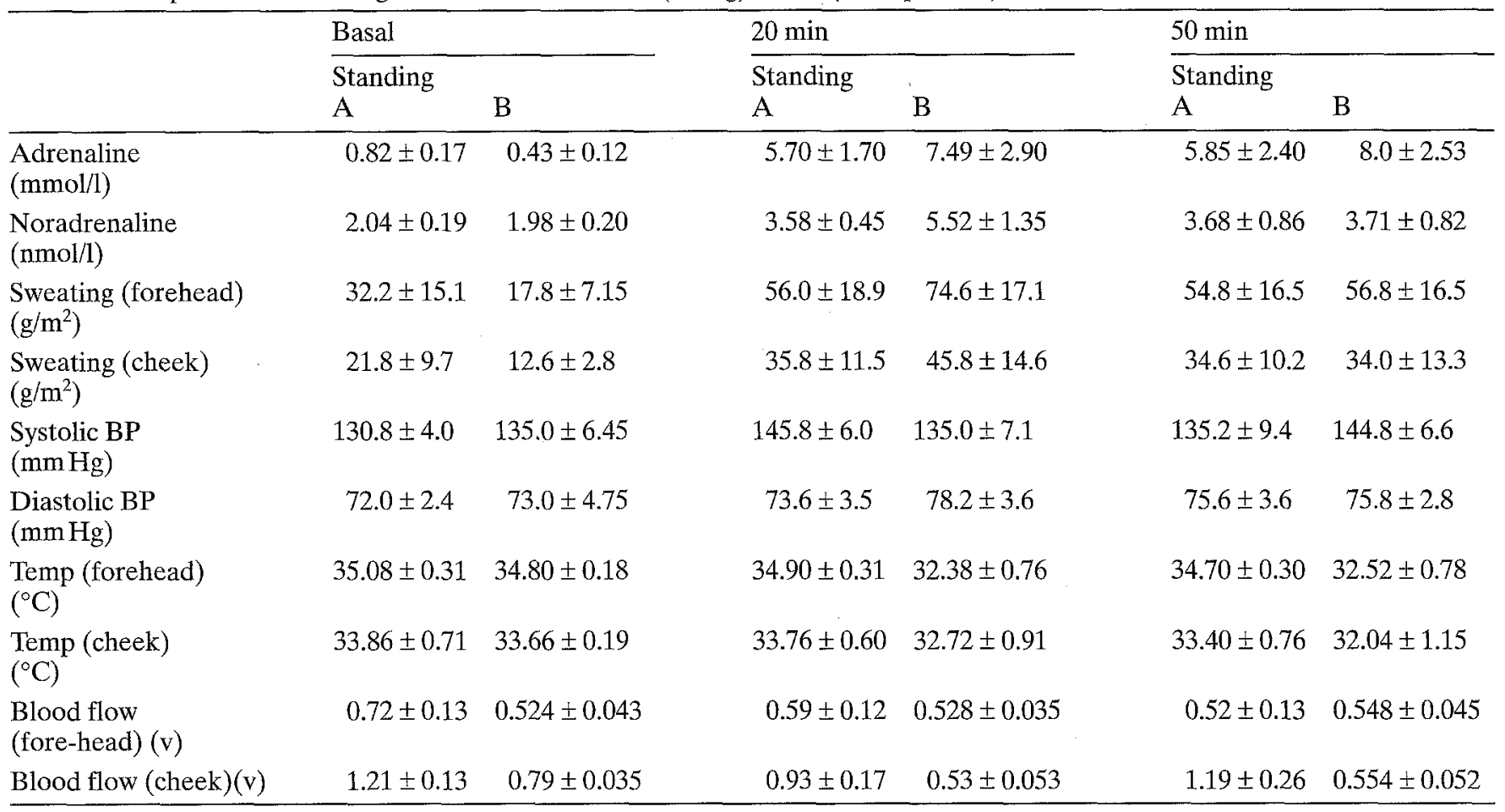

Data given as mean \pm SEM

to alpha-adrenoceptors [15], which may be enhanced during upright hypoglycaemia.

The physiological changes with posture were constant throughout the period of hypoglycaemia, but the increase in symptoms while standing and hypoglycaemic was only seen for the first tilt, and the effect was lost after 50 min of moderate hypoglycaemia. This confirms previous observations of adaptation to prolonged hypoglycaemia [3]. Explanations for this symptomatic reduction despite continued physiological stimuli have suggested that the brain can use alternative fuels such as lactate [16] but if this was the case then there should be a generalised reduction in symptoms during the second tilt and not just when the patients are standing. Further studies are needed to understand this apparent adaptation.

In conclusion, standing increases the symptomatic response to hypoglycaemia due to an increase in catecholamines and sweat production. The mechanism may be due to reduced cerebral blood flow and increased alpha-adrenoceptor activity. Further studies are needed to confirm or refute the hypotheses suggested. In practical terms, to improve patients' awareness of hypoglycaemia, it is obviously impossible to suggest to patients that they sleep standing up! But those patients who do have reduced awareness must pay particular attention to glycaemic control during the night, especially if excess alcohol [17] has been drunk or heavy exercise [18] taken.

Finally, there is no doubt from the results of this study that any scientific investigation of hypoglycae- mia in human subjects must be performed with the subjects all reclining at a similar angle.

Acknowledgements. The authors wish to thank D. Forster for catecholamine analysis, R.Mullinger for insulin analysis and Mrs.P.Lister for secretarial help. We also thank Ms. E. Simpson for technical support and all the patients for their cooperation and their time.

\section{References}

1. Tattersall RB, Gill GV (1991) Unexplained deaths of type 1 diabetic patients. Diabet Med 8: 49-58

2. Hirsch IB, Heller SR, Cryer PE (1991) Increased symptoms of hypoglycaemia in the standing position in insulin dependent diabetes mellitus. Clin Sci 80: 583586

3. Kerr D, Macdonald IA, Heller SR, Tattersall RB (1989) Adaptation to mild hypoglycaemia in normal subjects despite sustained increases in counterregulatory hormones. Diabetologia 32: 249-254

4. Ewing DJ, Clarke BF (1986) Autonomic neuropathy: its diagnosis and prognosis. Clin Endocrinol 64: 751754

5. Ryder REJ, Johnson K, Owens DR, Marshall R, Ryder AP, Hayes TM (1988) Acetylcholine sweatspot test for autonomic denervation. Lancet i: 1303-1305

6. DeFronzo RA, Tobin JD, Andres R (1979) The glucose clamp technique: a method of quantifying insulin secretion and resistance. Am J Physiol 237: E214-E223

7. Hepburn DA, Deary IJ, Frier BM (1992) Classification of symptoms of hypoglycaemia in insulin-treated diabetic patients using factor analysis: relationship to hypoglycaemia unawareness. Diabet Med 9: 70-75 
8. Macdonald IA, Lake DM (1985) An improved technique for extracting catecholamines from body fluids. J Neurosci 13: $239-240$

9. Ambler J, Janik B, Walker G (1983) Measurement of glycosylated haemoglobin in cellulose acetate membrane by mobile affinity electrophoresis. Clin Chem 29: 340-343

10. Langer SJ (1984) Presynaptic regulation of the release of catecholamines. Pharmacol Rev 32: 337-362

11. Heller SR, Macdonald IA (1991) Physiological disturbances in hypoglycaemia: effect on subjective awareness. Clin Sci 81: 1-9

12. Clutter WE, Brier DM, Shah SD, Cryer PE (1980) Epinephrine plasma metabolic clearance rates and physiologic thresholds for metabolic and haemodynamic action in man. J Clin Invest 66: 94-101

13. Heller SR, Macdonald IA, Herbert MH, Tattersall RB (1987) Influence of sympathetic nervous system on hypoglycaemic warning symptoms. Lancet ii: 946-948
14. Maggs D, Macdonald IA (1992) Disturbed thermoregulatory responses to sustained hypoglycaemia in long duration type 1 diabetes. Diabet Med 9 [Suppl 1]: $47 \mathrm{~A}$ (Abstract)

15. Van Zwieten PA, Tommerman PBMWM (1984) Central and peripheral alpha-adrenoceptors. Pharmacological aspects and clinical potential. Advanced Drug Reviews 13: 209-254

16. Maran A, Cranston I, Lomas J, Macdonald I, Amiel SA (1994) Protection by lactate of cerebral function during hypoglycaemia. Lancet 343: 16-20

17. Kerr D, Macdonald IA, Heller SR, Tattersall RB (1990) Alcohol intoxication causes hypoglycaemia unawareness in healthy volunteers and in patients with type 1 (insulin-dependent) diabetes. Diabetologia 33: 216-221

18. Zinman B, Murray F, Vranic A et al. (1977) Glucoregulation during moderate exercise in insulin treated diabetes. J Clin Endocrinol 45: 641-652 